\title{
The effects of REM sleep deprivation on the metabolic rates of male rats
}

\author{
JACQUELINE PUENTES, JOSE BAUTISTA, RASHMITA MISTRY, \\ NATHAN PHILLIPS, and ROBERT A. HICKS \\ San Jose State University, San Jose, California
}

\begin{abstract}
To confirm earlier speculation and to replicate the results of a single study, the effect of REM sleep deprivation on the oxygen consumption of male rats was monitored over a 10-day period. The data suggested an inverse relationship between these variables during the treatment period. However, we also identified variables for future research, which contribute ambiguity to the interpretation of this relationship.
\end{abstract}

Rechtschaffen and his colleagues (Bergmann, Kushida, Hennessey, Winter, \& Rechtschaffen, 1984; Kushida, Bergmann, Everson, Winter, \& Rechtschaffen, 1984) reported that during treatment, the food intake of rats that were totally deprived of REM sleep until death was $186.2 \%$ of pretreatment baseline levels, as compared with a $127.5 \%$ increase for the untreated controls during the treatment period. Paradoxically, they also reported that during the treatment period, the body weight of the REMdeprived rats declined $21 \%$ more than the untreated controls. To explain the fact that their REM-deprived animals both ate more and lost more weight, in a subsequent paper (Kushida et al., 1985) they estimated that the daily energy expenditure of the REM-deprived animals was $68 \%$ higher than that of the control animals during the treatment period. These post hoc estimates of energy expenditure were not derived from direct observation but rather were deduced from the differences in food intake reported for these animals. Martinez and Mendieta (1986), in a study completed in our lab, attempted to validate this assumption by measuring changes in the metabolic rates (e.g., oxygen consumption) of rats as a function of REM sleep deprivation (RSD). Since their data are unpublished, we have summarized them here in Table 1 . As is shown in Table 1, the oxygen consumption of the animals that were deprived of REM sleep for a 4-day period increased by almost $25 \%$ over baseline during treatment. Further, when the changes in oxygen consumption during treatment for the 2-day and 4-day RSD groups are compared with the controls, the overall pattern of these means suggests that RSD affected oxygen consumption in a doserelated fashion.

While these data appear to support the assumption that RSD increases metabolic rate, we view them with caution because the apparatus that was available to us for the measurement of oxygen consumption at the time of this

This research was supported by NIH-MBRS Grant GM 08192-11. Requests for reprints should be sent to Robert A. Hicks, Department of Psychology, San Jose State University, San Jose, CA 95192. experiment may have introduced a systematic methodsby-treatments stress effect that could have confounded the results. To explain, this apparatus required placing animals in relatively small chambers and then submersing these chambers under water. Therefore, it may have been the case that this apparatus induced stress by partially immobilizing the animals in a novel environment. This is important in that as Hicks and Sawrey (1978) demonstrated, REM-sleep-deprived animals show substantially higher levels of susceptibility to immobilizationinduced stress than do untreated control animals. Thus, the specific purpose of the present study was to replicate the effect reported by Martinez and Mendieta (1986) using an oxygen analyzer that minimized the potential confounding that may have been introduced by their apparatus. Consistent with the previous discussion, we predicted that relative to untreated controls, the RSD group would show increased oxygen consumption during the treatment period.

\section{METHOD}

\begin{abstract}
Animals
The animals were 18 male Sprague-Dawley rats that were 35 days old when they were delivered from the supplier (Simonsen Laboratories, Gilroy, CA). After a 10-day adaptation period, the animals were randomly assigned to one of three treatment conditions, that is, either the dry control (DC) group, the wet control (WC) group, or the RSD group, so that there were 6 animals in each group.
\end{abstract}

\section{REM Sleep Deprivation}

RSD was achieved using the water-tank procedure, which is described in detail by Hicks and Moore (1979). During the experiment, all of the animals were housed in 18.9-liter buckets that were modified so that the food and water were available ad lib from a feeder on the side of the cage. The top of each bucket was covered with wire mesh, and the water bottle was positioned so that the spout was within easy reach of the animal. During the treatment period, each animal in the RSD condition spent its time in the bucket on a $6.5-\mathrm{cm}$ platform that was surrounded by water $\left(19^{\circ} \mathrm{C}\right)$ to within $1 \mathrm{~cm}$ of the platform. The animals in the WC group were treated identically, with the exception that these animals spent the entire treatment period on a $16.5-\mathrm{cm}$ platform that was surrounded by water. These platforms were large enough to prevent the animals from falling into the water at the onset of REM sleep. Thus, this group served as a non-RSD control for exposure to the wet environment. The DC group spent the entire treatment period housed 
Table 1

Oxygen Consumption (Mean $\mathrm{kcal} / \mathrm{m}^{2} / \mathrm{h}$ ) Differences Between

Mean Baseline Days and Each Treatment and Recovery Day (Martinez \& Mendieta, 1980)

\begin{tabular}{lrrrrrrrr}
\hline \multirow{2}{*}{$\begin{array}{c}\text { Treatment } \\
\text { Group }\end{array}$} & \multicolumn{4}{c}{ Treatment Days } & & \multicolumn{3}{c}{ Recovery Days } \\
\cline { 2 - 5 } \cline { 6 - 8 } & \multicolumn{1}{c}{2} & \multicolumn{1}{c}{3} & \multicolumn{1}{c}{4} & & \multicolumn{1}{c}{6} & 7 \\
\hline RSD-4 days & 13.0 & 20.8 & 24.8 & 13.4 & & 5.0 & -22.6 & -27.4 \\
RSD-2 days & 6.8 & 6.9 & 2.2 & 5.0 & & 4.6 & -29.7 & -29.2 \\
WC & 2.0 & 2.4 & -0.8 & -9.4 & & -11.0 & -34.2 & -34.0 \\
DC & 6.8 & -12.2 & -14.6 & -19.0 & & -23.6 & -40.6 & -41.6 \\
\hline
\end{tabular}

Note-RSD = REM sleep deprivation; $\mathrm{WC}=$ wet control; $\mathrm{DC}=$ dry control.

in a dry RSD apparatus with a $16.5-\mathrm{cm}$ platform in place, and therefore served as a non-RSD control for exposure to the novel RSD apparatus.

\section{Metabolic Rate}

Metabolic rate was estimated by measuring oxygen consumption. To do this, air was drawn into a Plexiglas cylinder that measured $35.56 \mathrm{~cm}$ in circumference and $30.48 \mathrm{~cm}$ in height, that is, a chamber that was much larger than those used by Martinez and Mendieta (1986). Moisture was extracted from the air as it passed through Drierite desiccant before it reached a mass flow meter (Model FM-360, Tylan) that was connected to an output box (Model RO-32, Tylan). The flow meter was used to monitor a constant rate of approximately $1 \mathrm{liter} / \mathrm{min}$ of air through the system. Using a $T$ fitting, a sample of the air $(100 \mathrm{ml} / \mathrm{min})$ was drawn through an oxygen sensor (Model N-22M, Applied Electrochemistry, AMETEK) connected to an oxygen analyzer (Model S3A/1, Applied Electrochemistry, AMETEK), which read the percent of oxygen in the air. The sample of air was controlled using a flow control (Model R-1, Applied Electrochemistry, AMETEK). To help ensure consistency, the pressure of the air going to the oxygen sensor was also monitored using a manometer. During measurement periods, analog outputs from the oxygen sensor and the flow meter were digitized and stored on an Apple Ile computer. The actual oxygen consumption $\left(\mathrm{VO}_{2}\right)$ of each animal was calculated using standard equations (Withers, 1977) and followed procedures used by Phillips and Berger (1986) to measure $\mathrm{VO}_{2}$ during shallow torpor in pigeons. During each measurement period, this system took 1-sec samples and printed out the mean for every 15 -sec period. For each test, the $\mathrm{VO}_{2}$ of each animal was measured for $15 \mathrm{~min}$. The first $3 \mathrm{~min}$ of each test period were considered adaptation time to the apparatus and were disregarded. Thus, the overall mean for the last $12 \mathrm{~min}$ of each test period was used as the $\mathrm{VO}_{2}$ score for that test.

\section{Procedure}

When they were first received from the supplier, the animals were adapted to the lab for an 8-day period designed to acclimate these animals to the light-dark cycle and the experimental apparatus and procedures. Throughout the entire experimental period, each animal was handled for $10 \mathrm{~min}$ and weighed. During adaptation, each animal was placed in the metabolic chamber for $2 \mathrm{~min}$ (Days 1-4) and then for 5 min (Days 5-8). After this adaptation period, the daily $\mathrm{VO}_{2}$ tests for each animal were started. The first two tests (Days 9 and 10) were used to determine pretreatment baseline levels of $\mathrm{VO}_{2}$ for each animal. After the baseline testing was completed, animals were assigned to one of the three treatment groups. Following their 4-day exposure to either the RSD, WC, or DC treatments, all the animals were returned to the original housing conditions for a 4-day recovery period. Throughout baseline, treatment, and recovery, $\mathrm{VO}_{2}$ was measured every day for $15 \mathrm{~min}$ for each animal between 1130 and $1330 \mathrm{~h}$. The colony/test room was maintained at $22^{\circ} \pm 2^{\circ} \mathrm{C}$, and a 12:12-h light:dark cycle, with lights on at $0800 \mathrm{~h}$, was used throughout the entire experimental period.

\section{RESULTS}

First, as a rough check on the possibility of differential levels of treatment-induced stress, the daily weights of the animals were analyzed by computing a 3 (treatments) $\times 10$ (days) factor analysis of variance with repeated measures in the second factor (days), with the result that the main effect for treatments was not significant $[F(2,15)=2.10]$.

The $\mathrm{VO}_{2}$ means and standard deviations for each treatment group for each day are listed in Table 2. The data summarized in Table 2 were first analyzed by computing a 3 (treatments) $\times 10$ (days) factor analysis of variance. The main effects for both treatments $[F(2,15)=$ $8.38, p<.005]$ and days $[F(9,135)=22.62, p<.001]$ were significant, as was the treatments $X$ days interaction $[F(18,135)=3.47, p<.001]$. To further elaborate these data, post hoc analyses for each day were computed between each treatment group using the Newman-Keuls

Table 2

Means and Standard Deviations for Oxygen Consumption $\left(\mathrm{ml} \mathrm{o}_{2} / \mathrm{g} / \mathrm{h}\right)$ for Each Day for Each Treatment Group

\begin{tabular}{|c|c|c|c|c|c|c|c|c|c|c|}
\hline \multirow{2}{*}{$\begin{array}{c}\text { Treatment } \\
\text { Group }\end{array}$} & \multicolumn{2}{|c|}{ Baseline } & \multicolumn{4}{|c|}{ Treatment Days } & \multicolumn{4}{|c|}{ Recovery Days } \\
\hline & 1 & 2 & 3 & 4 & 5 & 6 & 7 & 8 & 9 & 10 \\
\hline \multicolumn{11}{|l|}{ RSD } \\
\hline $\boldsymbol{M}$ & 2.27 & 2.16 & 2.67 & 2.61 & 2.62 & 2.70 & 2.30 & 2.02 & 2.11 & 1.98 \\
\hline$S D$ & .20 & .20 & .20 & .27 & .27 & .12 & .24 & .99 & .14 & .13 \\
\hline \multicolumn{11}{|l|}{ WC } \\
\hline $\boldsymbol{M}$ & 2.20 & 2.13 & 2.41 & 2.52 & 2.54 & 2.50 & 2.29 & 2.14 & 2.03 & 2.03 \\
\hline$S D$ & .23 & .21 & .12 & .27 & .21 & .16 & .21 & .07 & .26 & .19 \\
\hline \multicolumn{11}{|l|}{ DC } \\
\hline$M$ & 2.28 & 2.17 & 2.23 & 2.18 & 2.16 & 2.14 & 2.14 & 1.98 & 2.04 & 1.98 \\
\hline$S D$ & .08 & .17 & .19 & .17 & .14 & .19 & .17 & .06 & .11 & .10 \\
\hline
\end{tabular}


Table 3

Levels of Significance Computed for Each Post Hoc Analysis of Between-Group Differences in Oxygen Consumption

\begin{tabular}{|c|c|c|c|c|c|c|c|c|c|c|}
\hline \multirow{2}{*}{$\begin{array}{l}\text { Groups } \\
\text { Compared }\end{array}$} & \multicolumn{2}{|c|}{ Baseline } & \multicolumn{4}{|c|}{ Treatment Days } & \multicolumn{4}{|c|}{ Recovery Days } \\
\hline & 1 & 2 & 3 & 4 & 5 & 6 & 7 & 8 & 9 & 10 \\
\hline $\begin{array}{l}\text { RSD vs. WC } \\
\text { RSD vs. DC } \\
\text { WC vs. DC }\end{array}$ & $\begin{array}{l}\text { n.s. } \\
\text { n.s. } \\
\text { n.s. }\end{array}$ & $\begin{array}{l}\text { n.s. } \\
\text { n.s. } \\
\text { n.s. }\end{array}$ & $\begin{array}{l}.1 \\
.01 \\
.05\end{array}$ & $\begin{array}{l}\text { n.s. } \\
.05 \\
.05\end{array}$ & $\begin{array}{l}\text { n.s. } \\
.01 \\
.01\end{array}$ & $\begin{array}{l}.05 \\
.01 \\
.01\end{array}$ & $\begin{array}{l}\text { n.s. } \\
\text { n.s. } \\
\text { n.s. }\end{array}$ & $\begin{array}{l}.05 \\
\text { n.s. } \\
.01\end{array}$ & $\begin{array}{l}\text { n.s. } \\
\text { n.s. } \\
\text { n.s. }\end{array}$ & $\begin{array}{l}\text { n.s. } \\
\text { n.s. } \\
\text { n.s. }\end{array}$ \\
\hline
\end{tabular}

Note-RSD = REM sleep deprivation; $\mathrm{WC}=$ wet control; $\mathrm{DC}=$ dry control.

statistical procedure. The results of these analyses are summarized in Table 3.

As is shown in Table 3, the differences between the $\mathrm{VO}_{2}$ means of the three groups were, for the most part, not significant during the baseline and recovery days. However, during the entire treatment period, the $\mathrm{VO}_{2}$ means of both the RSD and WC groups were significantly higher than those computed for the DC group. Finally, and most critically, at best the RSD-WC differences during treatment were only marginally significant and thus, overall, we prefer to consider the treatment-period $\mathrm{VO}_{2}$ means of these groups as similar.

\section{DISCUSSION}

Collectively, the data provided here provide only ambiguous support for the hypothesis that RSD increases metabolic rate. The lack of difference between the RSD and WC groups that we observed is at odds with the dose-related response between these variables that Martinez and Mendieta (1986) reported in their study, and these differences in outcome raise issues that require discussion.

First, as we described, both the RSD and WC conditions require that the animals be maintained on platforms surrounded by water during the treatment period. Although the diameters of these platforms differ, both of these treatments cause loss of REM sleep that is greater in the RSD group. Further, even though we maintain the animals in the same chambers throughout the entire experimental period, the addition of water during the treatment period may alter the novelty of the chamber and thus increase the likelihood that the RSD and WC animals experience the so-called "first-night effect" at the onset of the treatment period (i.e., suppression of REM sleep during the first night and possibly the second night when sleeping in a novel environment). Therefore, it may be the case that the loss of REM sleep was similar for both our RSD and WC groups, and if this speculation is correct, the significant increases in $\mathrm{VO}_{2}$ for these groups over the $\mathrm{DC}$ group during treatment would be viewed as support for the hypothesis. However, we did not record the sleep of our animals during the experiment, and as a consequence this conjecture cannot be verified. Further, since Martinez and Mendieta (1986) exposed their animals to the same treatment conditions and found $\mathrm{VO}_{2}$ differences between their RSD and WC groups, this interpretation of the lack of difference between our RSD and WC groups is not very convincing, and since there may be other possible reasons for the increase of the $\mathrm{VO}_{2}$ means of the RSD and WC groups during treatment, we are unable to draw this conclusion,

Another possible explanation for the lack of difference between the RSD and WC groups during treatment can be found in a common element of their treatment environments. That is, both of these groups were maintained in a wet environment for the 4-day treatment period, and exposure to water may increase heat loss, which in turn may increase metabolic rate. In this regard, Roussel and Bittel (1979) found that after depilating rats, their $\mathrm{VO}_{2}$ increased relative to undepilated controls. Although these animals were not exposed to water as ours were, depi- lation and wet fur both cause the loss of ability to retain heat, and thus the increase in $\mathrm{VO}_{2}$ that we noted for our RSD and WC groups during treatment may have reflected the animals' increased energy consumption to remain warm. While this possibility should be considered in future research, it does not account for the differences in outcome between this study and the Martinez and Mendieta (1986 study).

As is shown in Table 1, Martinez and Mendieta (1986) reported fairly substantial differences between their 4-day RSD and WC groups on each treatment day. All of these differences are significant. A possible factor that may have contributed to the relative magnitudes of the RSD-WC differences between their study and ours is the likelihood that their method of measuring $\mathrm{VO}_{2}$ introduced stress, while the method used here was designed to minimize this potential source of confounding. To a degree, this speculation can be supported by comparing the patterns of the $\mathrm{VO}_{2}$ means for the DC groups that are listed in Tables 1 and 2, that is, the means for groups that were not exposed to a wet environment during treatment. If one inspects the pattern of $\mathrm{VO}_{2}$ means for this group in Table 1 , it is clear that these means declined systematically as a function of exposure to the $\mathrm{VO}_{2}$ apparatus (similar patterns can be seen for the other treatments as well). This pattern suggests an adaptation effect, or put differently, a systematic decline in stressfulness of confinement in this apparatus as a function of experience with it. In contrast to the pattern of the means listed in Table 1, the pattern of the DC group's $\mathrm{VO}_{2}$ means and those of the other treatment groups that are presented in Table 2 do not suggest systematic reductions of $\mathrm{VO}_{2}$ as a function of exposure to the $\mathrm{VO}_{2}$ test apparatus. Collectively, these data may be viewed as suggesting differences in the stressfulness of the $\mathrm{VO}_{2}$ test situation between the Martinez and Mendieta (1986) study and ours. Recently, after reviewing the literature on the relationships between RSD and drive-related behaviors (Martinez, Bautista, Phillips, \& Hicks, 1991), we argued, as Dement (1965) had in an earlier paper, that RSD and stressful manipulations seem to interact to potentiate strikingly high levels of generalized drive that are not apparent when RSD is the sole manipulated variable. In this context, the difference in the outcome between the Martinez and Mendieta (1986) study and ours suggests the need in future research to measure metabolic rate as a function of the systematic covariation of levels of both RSD and stress as a means of defining the possible interaction of these variables that we have suggested here.

Finally, collectively, the data considered here suggest that during treatment, there is an inverse relationship between amount of REM sleep and the metabolic rates of rats. However, in view of the previous discussion, it is not prudent to argue that RSD is the only factor that contributes to this relationship.

\section{REFERENCES}

Bergmann, B., Kushida, C., Hennessey, C., Winter, J., \& RechtSCHAFFEN, A. (1984). Paradoxical sleep deprivation in the rat: II. Energy consumption. Sleep Research, 13, 185.

DEMENT, W. C. (1965). Recent studies on the biological role of REM sleep. American Journal of Psychiatry, 122, 404-408.

HicKs, R. A., \& MoORE, J. D. (1979). REM sleep deprivation diminishes fear in rats. Physiology \& Behavior, 22, 689-692.

Hicks, R. A., \& SAWREY, J. M. (1978). REM sleep deprivation and stress susceptibility in rats. Psychological Record, 28, 187-191. 
Kushida, C., Bergmann, B., Everson, C., Winter, J., \& RechtSCHAFFEN, A. (1984). Paradoxical sleep deprivation in the rat: I. Physiological effects. Sleep Research, 13, 191.

Kushida, C., Bergmann, B., Fang, V. S., Leitch, C. A., OberMEYER, W., RefetofF, S., SCHOEller, D. A., \& ReChtschafFen, A. L. (1985). Physiological and biochemical effects of paradoxical sleep deprivation in the rat. Sleep Research, 15, 219.

Martinez, R. K., Bautista, J., Phillips, N., \& Hicks, R. A. (1991). REM-sleep deprivation and the food-consumption patterns of male rats. Bulletin of the Psychonomic Society, 29, 421-424.

MArtinez, R. K., Me Mndieta, E. (1986, May). REM sleep deprivation increases the metabolic rates of rats. Paper presented at the meeting of the Western Psychological Association, Seattle, WA.
Phillips, N., Berger R., (1986, March). Thermoregulatory responses to diurnal glucose infusions during nocturnal sleep in fasting pigeons. Paper presented at the Sixth European Winter Conference on Brain Research, Avoriaz, France.

Roussel, B., BitTel, J. (1979). Thermogenesis and theromolysis during sleeping and waking in the rat. Pflugers Archives European Journal of Physiology, 382, 225-231.

WITHERs, P. C. (1977). Measurement of $\mathrm{VO}_{2}, \mathrm{VCO}_{2}$, and evaporative water loss with a flow through mask. Journal of Applied Physiology: Respiratory Environmental Exercise Physiology, 42, 120-123.

(Manuscript received July 5, 1991.) 